\title{
Avis + Elsmere, Time as a Design Tool for Community
}

\author{
TADD HEIDGERKEN \\ University of Detroit Mercy
}

Avis + Elsmere, a project in Detroit, offers a model for collaborative design as the genesis of architecture rather than the solution for architecture. The project rose from a belief that spaces resulting from collaborative, community-led design processes responding to contextual challenges over time create places that strengthen communities. The project is the product of a robust relationship between the clientcollaborator, a diverse community stakeholder group, and local architects, educators, and students. It grew from a neighborhood actively tying itself together through art and youth over eight years.

In 2010 residents of Southwest Detroit approached Detroit Mercy School of Architecture's Detroit Collaborative Design Center (DCDC) to discuss strategies to leverage the neighborhood's strengths to promote holistic development of youth in urban settings through building relationships, community education, and passion-driven projects. At that time Young Nation aimed to build meaningful relationships between neighborhood youth and elders using low-rider car club and street art cultures. Young Nation is now the client-collaborator for Avis + Elsmere, which now houses the organization's first permanent office, flexible community event space used for open studios and youth workshops, and a leasable tenant space.

Over the last decade, Young Nation brought architectural educators and students from adjacent communities to build temporary interventions and permanent infrastructure based on expansive community planning discussions. In 2010 proposals and temporary installations developed into a permanent street art gallery and indoor/outdoor workshop, The Alley Project (TAP Gallery). These projects crystallized the community's desire for a new space. Most recently, Young Nation then invited the architecture firm Et al Collaborative to contribute to the design of an anchoring neighborhood gathering place at Avis + Elsmere.

Avis + Elsmere spaces and materials resulted directly from the collaborative design process and speak to the neighborhood's identity. The north facade extends out from a large community living room onto an enclosed 'front porch,' that follows the line of neighboring porches. This space brings the activity of TAP Gallery to the front of the building and the main corners of the neighborhood. The mural enveloping the project was designed by a late street artist and completed in

\author{
CEARA O'LEARY \\ University of Detroit Mercy
}

tribute by an alumnus of the youth program. A metal screen fabricated by local iron workers provides security and allows for transparency while referencing the wrought iron fences prevalent in the neighborhood. The project faces an unrealized plaza, also designed by neighbors, DCDC and Et al, which will include market space, a stage, and a skate park to be built as community resources allow.

Avis + Elsmere is also now the hub of a new master plan developed by the community and the original collaborative design group that started the conversation in 2010 . This plan connects several neighborhood organizations via an extension of TAP Gallery into the larger network of area alleyways.

Avis + Elsmere is sited in a social context that uses it as a point of departure and a goal post. The project is a living organism composed of a multitude of people and perspectives constantly shifting direction. 


\section{Avis + Elsmere}

\author{
Time as a Design Tool for Community
}

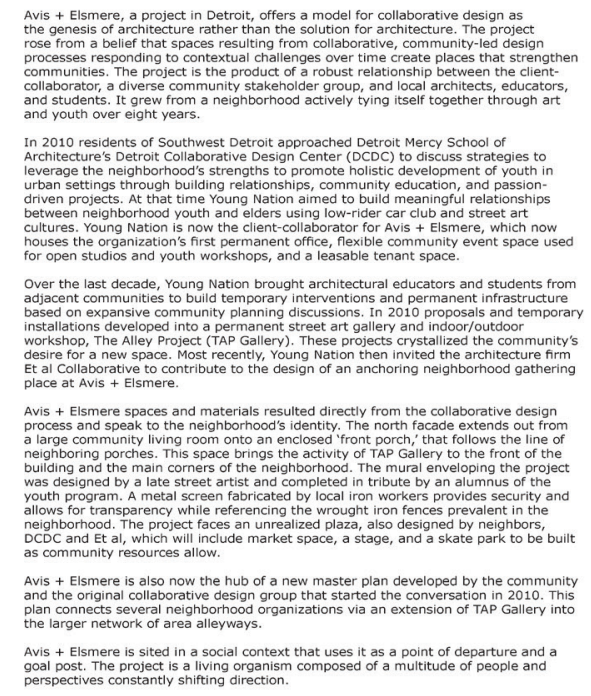

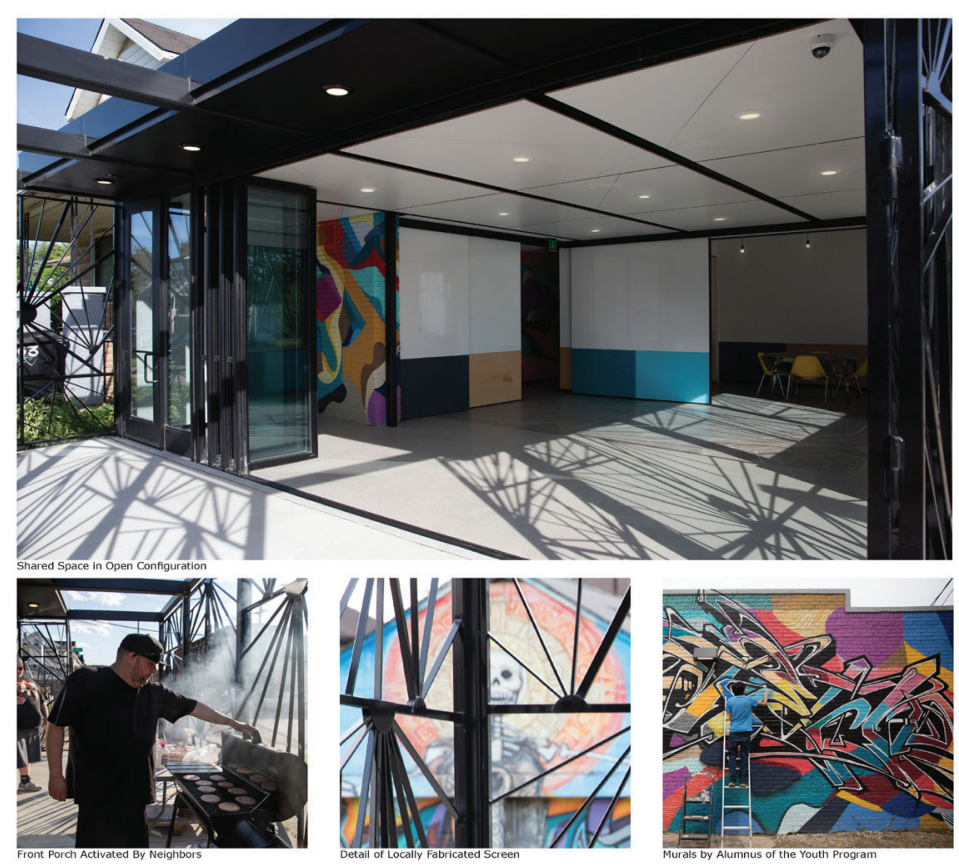
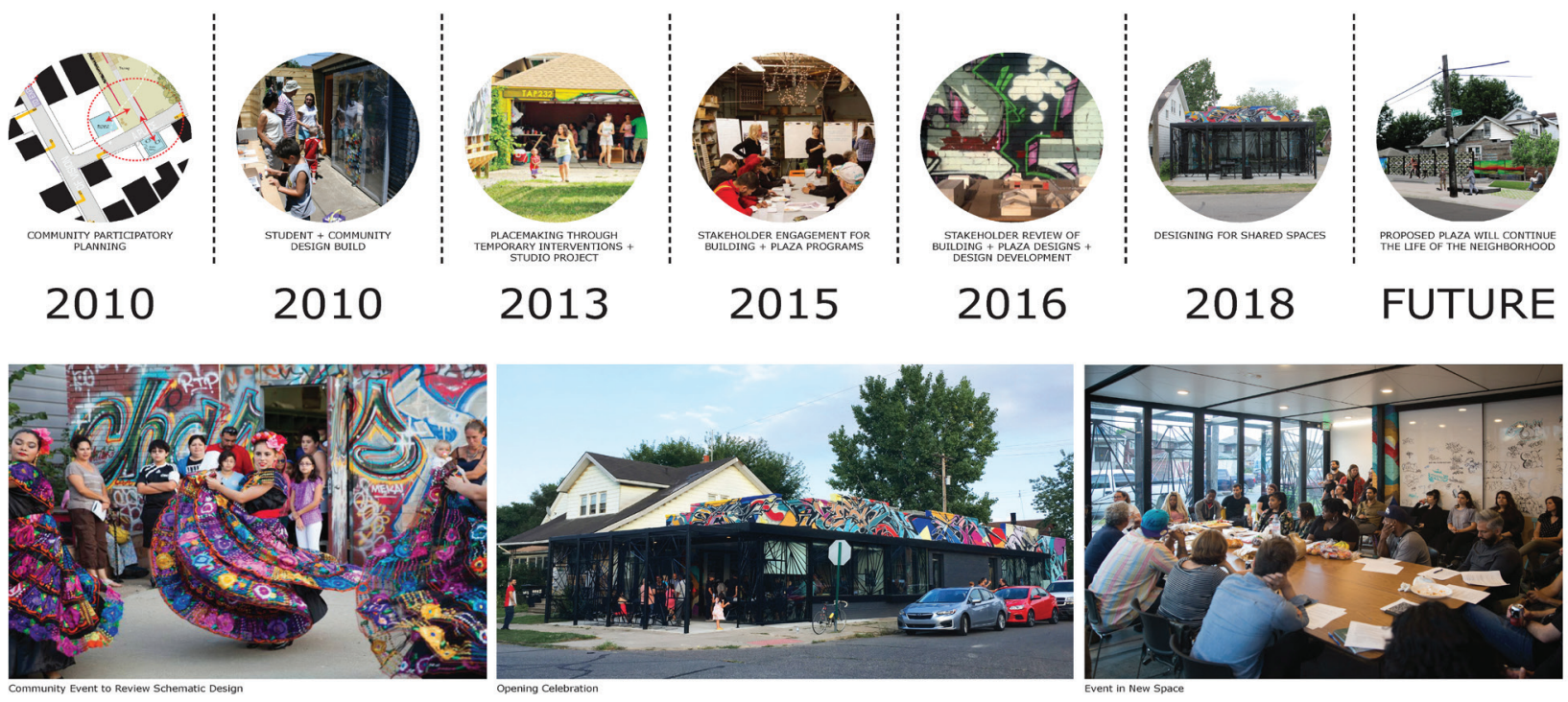
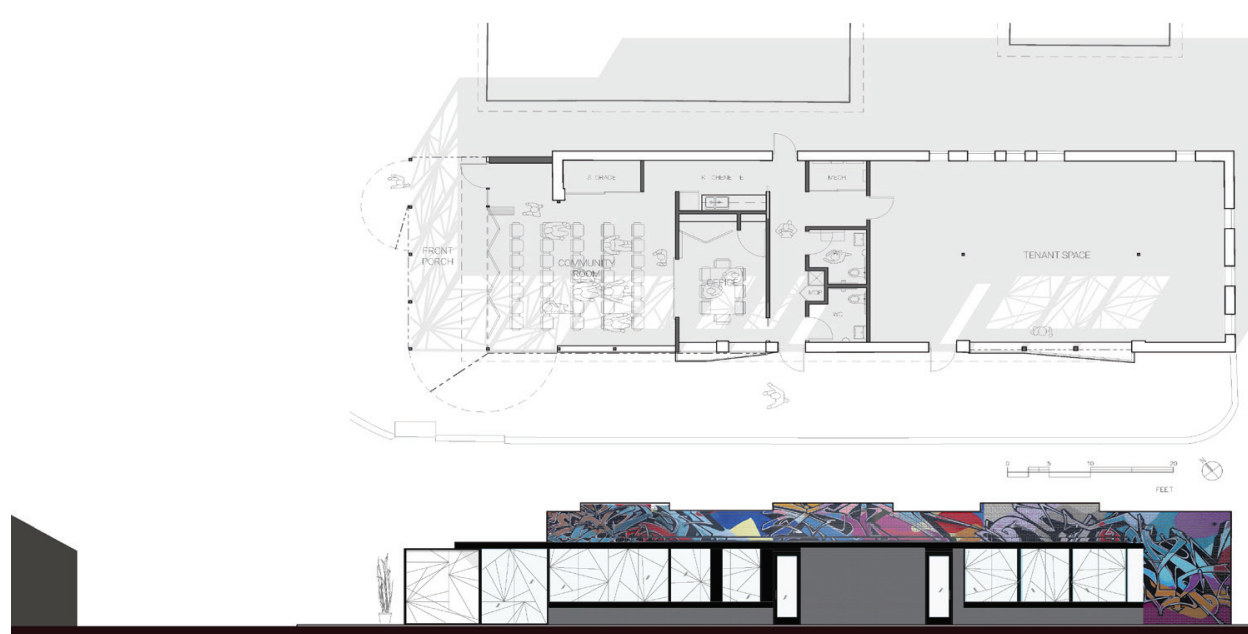